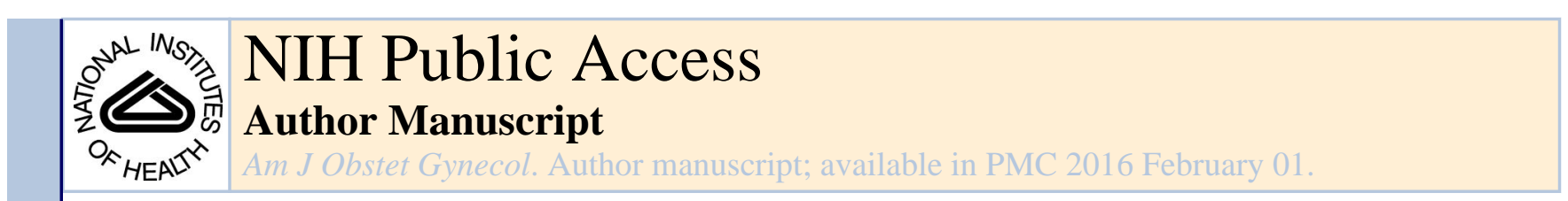

Published in final edited form as:

Am J Obstet Gynecol. 2015 February ; 212(2): 167-170.e1. doi:10.1016/j.ajog.2014.10.1094.

\title{
Creating and Selling Embryos for "Donation": Ethical Challenges
}

\author{
Robert Klitzman, MD and \\ Professor of Psychiatry; Director, Masters of Bioethics Program, Columbia University \\ Mark V. Sauer, MD \\ Professor of Obstetrics and Gynecology, Columbia University
}

\section{Abstract}

The commercial creation and sale of embryos has begun, posing a series of ethical questions that have received little scholarly attention. Some of the concerns that arise are similar to those posed by the sale of gametes, while other issues differ markedly. Questions emerge, firstly, regarding the rights of the unborn children - their ability to know their biological parents. Companies that create human embryos de novo may wish to keep gamete providers anonymous. Many of these offspring will thus never learn that their parents are not their biological parents. Yet, such disclosures regarding not only one, but both of these biological parents - may be important for these individuals; and lack of this knowledge may impede their physical and psychological health. Secondly, questions surface regarding the fees that providers should charge for embryos, and whether these amounts should vary based on the traits of one or both of the gamete donors. Some prospective parents may seek specific traits in a baby (e.g., height or eye/hair coloring), prompting creation of embryos from two gamete donors who possess these characteristics. Thirdly, ownership of embryos created without an advanced directive by patients poses dilemmas - e.g., disposition of any remaining embryos. Fourthly, guidelines do not yet exist to limit the number of embryos sold from each pair of gamete donors. Hence, unbeknownst to each other, full siblings could potentially meet, get married and procreate. This discussion has several critical implications for future practice, and professional education and policy. Patients with diseases associated with genetic tests may well ask obstetricians, gynecologists and other physicians about these techniques and practices. Clinicians can refer such patients to Assisted Reproductive Technology specialists, but familiarity with the basic aspects of the issues and complexities involved could aid themselves and their patients Several of these issues can be relatively easily addressed through guidelines from professional associations (e.g., limiting the number of embryos sold from each pair of gamete donors). As creation and sales of embryos will likely spread, consideration of appropriate

(C) 2014 Elsevier Inc. All rights reserved.

Corresponding Author: Robert Klitzman, MD, 1051 Riverside Drive; Mail Unit \#15, New York, NY 10032, Office Phone: 646-774-6912; Alternate Office Phone: 646-774-6913, Office Fax: 646-774-6955, rlk2@columbia.edu.

Publisher's Disclaimer: This is a PDF file of an unedited manuscript that has been accepted for publication. As a service to our customers we are providing this early version of the manuscript. The manuscript will undergo copyediting, typesetting, and review of the resulting proof before it is published in its final citable form. Please note that during the production process errors may be discovered which could affect the content, and all legal disclaimers that apply to the journal pertain.

The authors report no conflict of interest 
responses is critical in order to establish standards of care to help the future offspring, and ensure ongoing public trust.

\section{Keywords}

Ethics; Policy; Professionalism; Assisted Reproductive Technologies (ART); Risks/Benefits

Where life begins

Recently, a California company has begun creating and selling embryos, posing a range of ethical questions that have received little scholarly attention. Other clinics may now consider doing the same. Strikingly, this new market has received attention in the popular media ${ }^{1}$, but relatively little in the academic literature. Donated cryopreserved embryos can enable would-be parents who lack both sperm and eggs to have children, but several critical ethical dilemmas emerge. Indeed, only three countries (Russia, India and the United States) permit individuals to buy and sell human eggs. But, should we now permit buying and selling embryos, too, and if so how? Some individuals and organizations may immediately oppose this technology for religious or moral reasons. Some feminists and others have viewed the sale of eggs, and presumably embryos, as commodification, arguing that such markets cheapen human life. ${ }^{1}$ But can these procedures be ethically permissible, depending on how and for what indicators they are performed? What specific concerns may arise, and could guidelines address these?

Cohen and Adashi ${ }^{2}$ recently concluded that the ethical issues involved in creating embryos for donation are essentially no different than those posed by buying and selling human sperm or eggs or donating embryos. The only clear difference, they argue, concerns legal issues of parentage.

Yet, though some of the issues are similar, others differ markedly. Neither an egg nor a sperm, by itself, can become a human being, while an embryo certainly does, and therefore, arguably, warrants special consideration. A purchased gamete contains only half of the future child's DNA, whereas the embryo contains the entire genome. Moreover, creating embryos raise questions related to quandaries of "when life begins" and when "an individual commences". Some individuals believe that embryos have greater moral standing than do gametes. In our pluralistic society, broader ethical debates continue over that issue that we cannot resolve here. But that debate does not need to be resolved in order to examine particular critical issues that arise regarding embryo sales. Even regarding similar aspects of purchasing a gamete versus an embryo, commercial transactions involving embryos raise these dilemmas more acutely and forcefully, which should prompt us to revisit, rather than ignore these on-going controversies in this new context.

In this paper, we examine arguments pro and con, and suggest ways of potentially proceeding. Should embryos be thought of as a commodity, a product that may be bartered or sold in the open marketplace, or as something different, and if so, how? Questions arise concerning whether guidelines or parameters should be developed, and if so what - e.g., regarding anonymity or potential future contact or mandated or permitted exchange of 
information between offspring and gamete donors; limits in the number of offspring created from each batch of procured gametes; and the final dispositions of any embryos above this arbitrary number. The World Health Organization states that cells and tissues should be donated only without payment - except for reimbursement of reasonable expenses (e.g., loss of income) - and without any "advertising the need for or availability of cells...with a view to offering or seeking payment..."3 Yet international consensus documents are not always followed and do not constitute law; and in the US and several other countries, purchase and advertising of gametes regularly occurs.

Physicians from a wide variety of specialties should be aware of issues related to embryo as well as gamete donation, as they may well be asked questions regarding these techniques and practices. Patients with diseases associated with genetic tests may ask internists, obstetricians, pediatricians, psychiatrists and others about whether in the future to screen embryos, or purchase others' gametes or embryos from nonaffected donors, instead of using their own. Clinicians can refer such patients to ART specialists, but familiarity with the basic aspects of the issues and complexities involved could aid themselves and their patients.

Currently, this practice of selling embryos may be relatively limited in scope, but the number of providers doing it remains wholly unknown. Even if it may not be widespread presently, it will undoubtedly become far more prevalent, as have other new Assisted Reproductive Technologies (ARTs). The unique nature of the embryo as an object for sale makes the ethical questions raised critical.

Arguably, the different possible indications for embryo donation affect the ethical justifications in each case. For couples in which both members lack gametes, the procedure may be ethically justifiable, depending on how it is performed. Yet couples who purchase embryos to achieve offspring with particular desired non-medical characteristics (e.g., blond hair and blue eyes) pose several concerns.

Questions arise, too, concerning the rights of the unborn children - their ability to know their biological parents. Presumably, many of these offspring will never learn that their biological parents are not their parents. Companies that create human embryos de novo, and gamete donors themselves may wish to keep donations anonymous. Currently, many sperm or egg recipients do not tell their child that he or she was conceived using someone else's egg or sperm, fearing that the child will love them less. Yet research has suggested that most adults conceived using donor sperm want information about their donors, and think it should be provided. ${ }^{4}$ Some offspring inadvertently find out later (e.g., if a relative discloses the information, or the offspring discovers medical or legal documents) and may as a result feel disturbed, confused, mistrustful and alienated. With a donated embryo, parents may be even more reluctant to disclose that donation occurred, since neither of them is biologically related to their offspring. Hence, with many cases of embryo donation, no contact will probably ever occur between both - not only one - of these biological parents and their offspring. Yet, such disclosures may be important for these individuals, who may gain knowledge that can aid their physical and psychological health., 5 Gamete donors may, for instance, later discover genetic cancers or other serious familial diseases that would be 
important and useful information to these offspring. Many predictive genetic markers are best interpreted in the context of known family medical history.

Offspring may also want to know from whom they are descended for the knowledge in and of itself - to know their "roots". They may also reflect differently on their own identity if they know that they were created from embryos produced by individuals who never met and had nothing, knowingly, in common. Moreover, their biological parents each in fact provided their gametes for money, and thereby created the offspring partly for monetary self-gain, rather than love or altruism alone. Arguably, offspring have a right to know this information. One might argue that such disclosures may cause harm. But data from sperm donation suggest that the benefits of disclosures outweigh the possible risks. ${ }^{4}$

Questions arise, too, concerning how much providers or agencies should charge for embryos. The American Society of Reproductive Medicine (ASRM) has stated that women donating eggs may be compensated for their time and the risk involved. Payment, however, should not be for the eggs per se, but for the service rendered, and not tied to the quality of eggs. Unfortunately, many donor egg agencies and fertility clinics pay more for eggs from women with more perceived desirable pedigrees (e.g., higher SAT scores), and "proven" successful past donation. ${ }^{7}$

Desires of some prospective parents for specific traits in a baby (e.g., height or eye/hair coloring) can prompt creation of embryos from two gamete donors who each have these traits. Since egg donor compensation has varied based upon desired attributes, the costs of embryos may also reflect the desirability of perceived traits. Questions thus emerge of whether "bidding" for highly valued embryos should be allowed (with sale to the highest bidder, driven by market demand) and embryos deemed less desirable should be "discounted". Wealthy prospective parents may be able to bid competitively for embryos from gamete donors more extensively screened for health, beauty, athleticism, intellect, or avoidance of various mutations or less desirable traits, widening gaps between the haves and the have-nots, potentially fostering inequality and injustice. Future selection for or against certain traits (e.g., from obesity or homosexuality) may promote misunderstandings that genes "cause" certain traits that instead may result from complex interactions of both nature and nurture.

ASRM issues guidelines, but neither systematically monitors nor enforces them, and a portion of clinicians fail to follow these recommendations. For instance, ASRM recommends that donors be over 21 years of age, but over $40 \%$ of clinics appear to target younger women, who generally have better quality eggs, but may not have fully considered the long-term consequences of donation. ${ }^{8}$ Nonetheless, these guidelines serve critical roles, establishing standards of practice to which many providers commonly appear to adhere. ASRM could thus consider issuing additional guidelines that the costs of embryos offered to patients should not be linked to perceived desirable qualities.

Ownership of embryos created without an advanced directive by patients pose dilemmas, too. What if the creating party, corporate or professional, goes bankrupt - as did the Icelandic biobanking company, DecodeGenetics, resulting in ownership of all its genetic 
data by a British holding company? What if one or both gamete donors change their mind, and demand either access to the embryos for their own personal use, or destruction of the embryos? They may have signed a contract that defines the nature of their intent at the time of donation, but is it enforceable, and if so, in perpetuity? Questions emerge if the individuals who purchased the embryos wish to re-sell or donate them to others, or divorces after buying, but before using them.

Additionally, unbeknownst to each other, full siblings could potentially meet, get married and procreate. Embryo banks may argue that this event is unlikely, since these offspring may be born all over the country. But people move, and companies are located in particular regions from which they disproportionately obtain patients. Moreover, no guidelines limit how many embryos these programs create and sell; and the buyers are not followed over time. Egg donor and embryo registries are desirable, but don't yet exist. Until they do, intermarriage, although not very likely, is entirely possible.

Guidelines also do not exist to limit the number of prospective parents who could buy embryos from a given pair of gamete donors. Cohen and Adashi argue that concerns about potential intermarriage among children born through embryo sales "apply equally" to children born from single gamete donors, and can be handled through similar regulations and procedures.2 But the situations differ significantly, since offspring from the same sperm donor, but different mothers, are half siblings, and share only half their DNA. Offspring from the same batch of embryos (i.e., the same egg as well as sperm donors) would be full siblings, and can share their entire DNA. The risks of recessive diseases in their offspring are thus far higher.

Several of these issues can be relatively easily addressed through guidelines from ASRM (e.g. limiting the number of purchasers of embryos from each pair of gamete donors). As this practice will likely spread, appropriate guidelines are critical to establish as standards of care for the benefit of the future offspring, and to ensure ongoing public trust.

\section{Acknowledgements}

We would like to thank Jennifer Teitcher, B.A., and Patricia Contino, M.F.A., both of the Columbia University Masters of Bioethics Program, for their assistance with this manuscript.

Funding for this project was supported by Grant Number UL1 RR024156 from the National Center for Research Resources (NCRR).

\section{References}

1. Zarembo, A. [Accessed August 14, 2014] An ethics debate over embryos on the cheap. The Los Angeles Times. 2012 Nov 19. Available at http://articles.latimes.com/2012/nov/19/local/la-me embryo-20121120

2. Cohen IG, Adashi EY. Made-to-order embryos for sale - a brave new world? N Engl J Med. 2013 Jun 27.368:2517-2519. [PubMed: 23574034]

3. The World Health Organization. [Accessed September 12, 2014] WHO Guiding Principles on Human Cell, Tissue and Organ Transplantation. Endorsed by the sixty-third World Health Assembly in May 2010, in Resolution WHA63.22. http://www.who.int/transplantation/en/. 
4. Mahlstedt PP, LaBounty K, Kennedy WT. The views of adult offspring of sperm donation: essential feedback for the development of ethical guidelines within the practice of assisted reproductive technology in the United States. Fertil Steril. 2010; 93(7) 223622246.

5. Wydra M, O'Brien KM, Merson ES. In their own words: adopted persons experiences of adoption disclosure and discussion in their families. J Fam Soc Work. 2012; 15(1):62-77.

6. Brodzinsky DM. Children's understanding of adoption: developmental and clinical implications. Prof Psychol Res Pr. 2011; 42(2):200-207.

7. Levine AD. Self-regulation, compensation, and the ethical recruitment of oocyte donors. Hastings Cent Rep. 2010; 40(2):25-36. [PubMed: 20391847]

8. Keehn J, Holwell E, Abdul-Karim R, Chin LJ, Leu CS, Sauer MV, et al. Recruiting egg donors online: an analysis of in vitro fertilization clinic and agency websites' adherence to American Society for Reproductive Medicine guidelines. Fertil Steril. 2012; 98(4):995-1000. [PubMed: 22840240] 


\section{Table I}

Ethical challenges and questions posed by companies making and selling embryos

- Questions about the moral status of the embryo

- $\quad$ Ethical justification may vary with indications for embryo donation (i.e., medical vs non-medical research)

- $\quad$ Rights of unborn child

- Arguably, offspring have a right to know that their parents are not their biological parents and such disclosure would be beneficial

- Currently, gamete donors are anonymous, but problems can ensue.

- Offspring won't be able to know either biological parent's relevant medical or genetic history

- $\quad$ But will the child eventually

$\checkmark \quad$ Be told that he/she was created from a purchased embryo?

$\checkmark \quad$ Be able to contact biological parents?

$\checkmark$ Do the rights of offspring to know their parents outweigh the rights of donors to remain anonymous?

- How much will embryos be?

- $\quad$ Made to order based on traits?

- $\quad$ Companies seek to make embryos with desired traits

- Will certain traits be selected for or against, promoting eugenics?

$\checkmark \quad$ Could foster inequity and injustice

- How much to charge?: Concerns about commodification

- $\quad$ Should the price of embryos vary with an embryo's traits?

- Questions of ownership (e.g., if a company goes bankrupt)

- $\quad$ Risks of intermarriage

- Should the number of purchasers of embryos created from a given sperm and egg donor be limited?

$\checkmark \quad$ If so, what should the maximum be?

- Otherwise, could pose harms to subsequent generations 